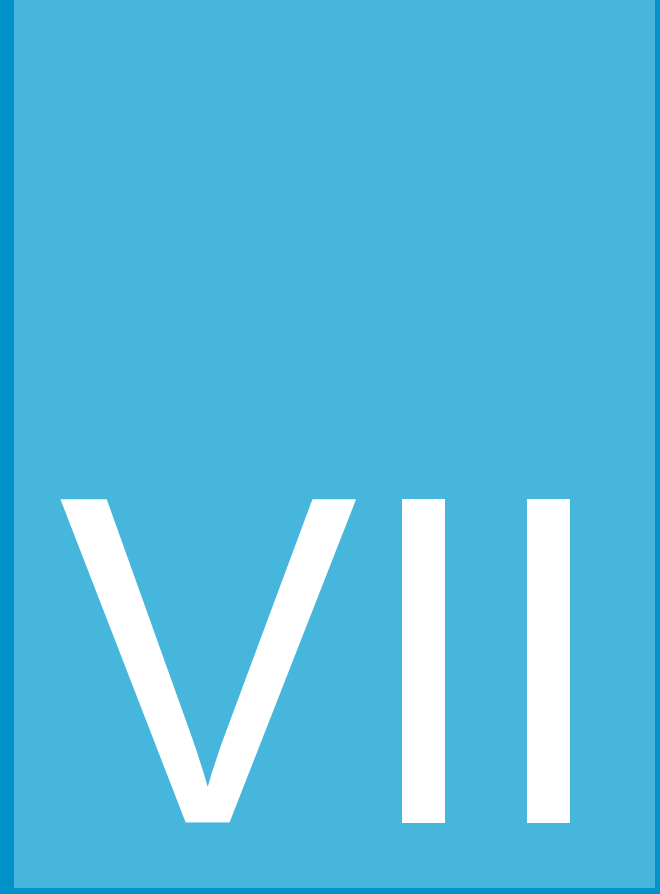

\title{
DETRÁS DE LA REVOLUCIÓN ECLESIAL
}

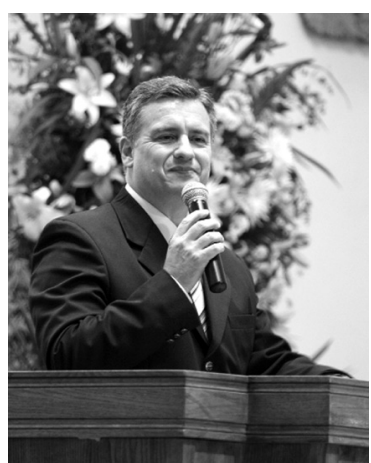

\section{Daniel Oscar Plenc}

Bachiller en Teología por la Universidad Adventista del Plata, Argentina. M.A. por la Universidad Adventista del Plata. Th. D. por el Seminario Adventista Latinoamericano de Teología, Argentina. Profesor visitante a nivel nacional e internacional. Docente Principal del Facultad de Teología de la misma institución. Actualmente se desempeña como director del Centro de Investigación White en Argentina. Ha publicado numerosos artículos eruditos y de divulgación. Ponente y conferenciante internacional. 


\section{Resumen}

Análisis crítico de las últimas publicaciones de Russell Burrill en relación a la misión y liderazgo de la Iglesia Adventista. Se presenta una revisión de estos escritos a la luz de la Biblia, escritos de Ellen White y de autores misionólogos comtenporáneos.

Palabras clave: Discipulado, grupos pequeños, eclesiología.

\section{Abstract}

Critical analysis of recent publications Russell Burrill in relation to the mission and leadership of the Adventist Church A review of these writings in the light of the Bible, writings of Ellen White and contemporaneous missiologists authors.

Keywords: Discipleship, small groups, ecclesiology. 


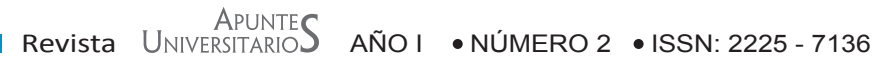

\section{Introducción}

Una nueva trilogía de libros ha estado dando que hablar en los círculos de lectores adventistas interesados en la iglesia, su misión y crecimiento. Se trata del autor Rusell Burrill que ha publicado: Revolution in the Church (no traducido); Radical Disciples for Revolutionary Churches (Fallbrook, California: Hart Research Center, 1996), traducido al español como Discípulos modernos para Iglesias revolucionarias, trad. Claudia Blath (Buenos Aires: Asociación Casa Editora Sudamericana, 2008); y The Revolutionized Church of the $21^{\text {st }}$ Century (Fallbrook, California: Hart Research Center, 1997), traducido al español como: La iglesia revolucionada del siglo XXI, trad. Claudia Blath (Buenos Aires: Asociación Casa Editora Sudamericana, 2007).

Revolution in the Church, libro que ha producido un cierto impacto en las Iglesias adventistas de la División Norteamericana, plantea un modelo de ministerio laico tomado de la Biblia y de Elena G. de White. En su segunda obra Discípulos modernos para Iglesias revolucionarias, el autor propone "una nueva interpretación del término discipulado" (p. 4). Desde el comienzo se hace claro que se trata de una reacción contra la pasividad de sectores del adventismo moderno (básicamente el norteamericano blanco) que se limita a "asistir y pagar" (p. 4). Se propone una reevaluación en el estilo de evangelización. Promueve la actividad y el compromiso de los discípulos en el ministerio (p. 5). Este discipulado requiere instrucción, en especial de los nuevos creyentes. La obra está animada por un propósito triple: "1.- Establecer el discipulado concienzudamente como el objetivo del proceso de evangelización. 2.- Definir bíblicamente el discipulado. 3.- Examinar el proceso de evangelización" (p. 6).

Un punto importante en la argumentación del autor es aclarar el lugar del bautismo en la evangelización. Alega que muchos pastores adventistas han sido influenciados por el fundador del Movimiento de Crecimiento de Iglesia, Donald McGavran, en un concepto que no es bíblico. Al desarrollar el tema se dirige a la Gran Comisión de Mateo 28:16-20.

El autor propone también reorganizar las iglesias sobre la base del Nuevo Testamento. En este sentido prefiere pensar que el origen de la iglesia están en la gran comisión y no en el Pentecostés (p. 20).

Un gran espacio se dedica a la difusión de lo que es un discípulo. Donald McGavran separó el discipulado en dos etapas: discipular (el contacto inicial de las personas con Cristo) y perfeccionar (edificar a las personas en la fe). Burrill considera que esta división no es bíblica y una confusión misionológica. Entonces habla del discípulo como de alguien que aprende, 
es decir como una persona que tiene una relación de aprendizaje con el Maestro. Cita textos como Mt 10:24,25; Lc 14:26, 27, 33; Ju 8:31, 32; 13:34, 35; $15: 8$.

En esto se concentra la tesis del autor: en afirmar que el discípulo no es quien ha tenido un encuentro inicial con Cristo sino quien ha experimentado el llamado a hacer discípulos (p. 35). También combate la idea de que alguien pueda ser bautizado sin convertirse en miembro de iglesia. Dice que el mandato de la gran comisión es hacer discípulos y que el bautismo simboliza la entrada al ministerio, no un simple reconocimiento de Cristo como Salvador (p. 38).

Uno de los tópicos elegidos en este volumen es el difícil asunto de la relación entre la iglesia y la cultura. Dice que en el Concilio de Jerusalén (Hch 15) la iglesia tuvo que definir lo que era el cristianismo y lo que era cultural, y lo hizo con éxito. Entonces piensa en la Iglesia Adventista del Séptimo Día dirigida por líderes locales y que se expresa en la cultura local. El desafío es separar la cultura de la esencia de la fe. Lo difícil parece ser determinar qué es culturalmente aceptable (p. 51). Propone no cambiar el mensaje sino la forma de presentarlo para ser una iglesia culturalmente relevante. Se plantea bien la dificultad con la aculturación respecto de la pérdida de identidad o de relevancia. Es correcta su observación: "Algo que la iglesia debe evitar mientras procura hacer que su mensaje sea culturalmente relevante es la tendencia a adaptarse a la cultura simplemente porque 'funciona'" (p. 55).

Otro punto que se subraya bastante es el de la autosuficiencia del discípulo en contraste con la dependencia espiritual de otros o de los pastores. El autor está en contra del concepto de "pastor sustentador" de iglesia locales dependientes del ministerio remunerado. Argumenta que los primeros pastores adventistas eran evangelizadores y plantadores de iglesias y no ministros de congregaciones locales. Los lugares del mundo (tercer mundo) donde se sigue empleando la idea del adventismo original experimentan mayor crecimiento. El modelo bíblico apuntaría a un pastor capacitador/ equipador, con libertad para evangelizar. Cree además que los pastores autóctonos favorecen el crecimiento.

El autor apunta también contra la dependencia de los edificios de iglesia y de una organización institucional al estilo católico (para usar sus palabras). Menciona la carencia de templos en los primeros siglos del cristianismo y su predilección por las iglesias hogareñas dirigidas por laicos, con una concentración de los recursos para la misión. 
En el resto del libro el autor hace su propia aplicación de "la teología de la gran comisión" (p. 65). Lo primero aquí sería recordar que la iglesia es un cuerpo, al cual deben integrarse los bautizados y en cuyo contexto se desarrollan los dones (p. 67). Apunta luego al movimiento adventista como un movimiento laico.

Hay también una apelación a la historia y una propuesta concreta de regresar a las raíces metodistas del adventismo. Esto debido a la idea de John Wesley de reunir a los conversos en clases con reuniones semanales. El autor contrasta esta práctica con el estilo calvinista encarnado en George Whitefield.

Se hace también una defensa de las doctrinas de los tres ángeles de Ap 14 para lograr el discipulado. "La metodología adventista de evangelización, por lo tanto, debe centrarse en hacer la clase de discípulos ordenada por la gran comisión y el mensaje de los tres ángeles" (99).

Como estrategia para el discipulado fomenta: (a) los grupos pequeños, (b) la ordenación al ministerio por imposición de manos, (c) el descubrimiento de los dones espirituales, (d) el proceso de hacer nuevos discípulos, (e) no dependencia de sermones y del pastor ordenado.

Ciertos reconocimientos de dependencias intelectuales del mundo evangélico son positivas: "En los últimos años, la escuela de crecimiento de iglesia de McGavran ha tenido una influencia significativa en los círculos adventistas" (p. 81). ¿Por qué no agregar aquí el nombre de C. Peter Wagner y otros de esa misma escuela del Seminario Fuller, en California?

Algunas afirmaciones se parecen demasiado a los tradicionales argumentos pentecostales. Por ejemplo: "No es un asunto de 'exactitud de doctrina' contra las señales y los milagros. Si tenemos todas las doctrinas correctas pero no tenemos al Espíritu, entonces el adventismo no es la verdadera iglesia de Jesús" (p. 14).

La eclesiología de Burrill es difusa de a ratos, como cuando contrasta la iglesia esparcida con la iglesia reunida: "Por lo tanto, donde esté la gente de la iglesia, allí está la iglesia. El lunes, la iglesia tal vez esté en la oficina, la fábrica o el club de salud. Cuando los miembros se interrelacionan con el mundo en sus ocupaciones y placeres, están siendo la iglesia esparcida" (p. 16). Alega que la iglesia esparcida debe ser la forma dominante (p. 16).

Algunas dicotomías son innecesarias. Así por ejemplo se opone el Pentecostés a la gran comisión: "La gran comisión es fundamental; el Pentecostés es secundario" (p. 19). Otra bifurcación inútil es la de diferenciar la misión adventista fomentada por Mateo 24:14 con la gran comisión de Mateo 28:16-20. La primera tendría como motivación la terminación de la 
obra para que Cristo vuelva y la segunda, la salvación de los perdidos (p. 72). Se dice que Mateo 24:14 alienta la proclamación y que Mt 28:19 fomenta el hacer discípulos. Esta última idea quedaría reforzada por Ap 14:6-12.

A veces el lenguaje empleado suena dispensacionalista: "Ahora estamos viviendo en la dispensación del Espíritu" (p. 41). Tampoco es feliz el empleo de términos usualmente católicos como "clero" y "laicos", que ciertamente no son adecuados en nuestra manera de hablar que tiene en cuenta el sacerdocio de todos los creyentes.

Llama la atención que el libro cita continuamente autores evangélicos sobre misión y crecimiento de iglesia y que nunca está ausente en este tipo de textos ciertas experiencias pentecostales como las promovidas por el legendario pastor Paul (David) Yonggi Cho, de las Asambleas de Dios de Corea, con la iglesia local más grande del mundo. Como quiera que sea, hay una tendencia a recurrir a estos modelos del mundo carismático, como el movimiento de oración.

Muchos de los argumentos respecto del liderazgo y la estructura de la iglesia pueden ser bien saludados por los movimientos caracterizados por el independentismo, contra lo cual Elena G. de White advirtió reiteradamente. Por otra parte, las preocupaciones del autor se presentaron en el contexto del adventismo norteamericano, a veces bastante diferente de la realidad de nuestras tierras. Suena por lo menos novedosa la sugerencia de que "las personas debieran ser ordenadas al ministerio en el momento de su bautismo por imposición de manos, como lo enseña el Nuevo Testamento" (p. 107).

El libro La iglesia revolucionada del siglo XXI viene con un prefacio de Aldwin Humphries, quien recuerda con admiración una reunión multitudinaria de la iglesia del Evangelio Completo, en Seúl, Corea, dirigida por Paul Yonggi Cho. El prefacio dice que hay fuentes (aunque no las cita) que sugieren que Cho leyó los libros El evangelismo y Obreros evangélicos de Elena G. de White cuando fundó los conceptos para crear la iglesia más grande del mundo (750.000 miembros y 50.000 grupos hogareños) (p. 4). El prologuista asume que el surgimiento de la estructura de grupos pequeños relacionales en el adventismo es como una nueva Reforma (p. 8). Deja finalmente en claro que el libro propone grupos pequeños de autogestión relacional en contraste con el individualismo norteamericano.

En el inicio Burrill dice que en la iglesia se han filtrado prácticas no bíblicas copiadas de sistemas de otras iglesias. Entonces se propone examinar la visión bíblica del funcionamiento de la iglesia. Cree que no se ha estudiado suficientemente los grupos pequeños desde el punto de vista 
teológico e histórico. Desea fundamentar la "comunidad" contra el "individualismo norteamericano" y el fenómeno de cristianos aislados que creen que pueden ser buenos cristianos sin ser parte de la iglesia (p. 16). La idea es formar "comunidades solicitas donde las personas verdaderamente se ministran unas a otras..." (p. 17), sin depender de pastores (que muchas veces están agotados y frustrados).

El fundamento teológico para la idea de comunidad se inicia con Dios expresado en Trinidad. La sugerencia va demasiado lejos, al decir que "la misma Deidad es un grupo pequeño" (p. 19). Habla de la necesidad de restaurar la imagen de Dios por medio de la comunidad, ya que "la imagen de Dios es comunidad" (p. 21). Continúa diciendo que el primer grupo pequeño aumentó cuando Dios creó a Adán y Eva y allí "Dios colocó un código genético de reproducción" en esta primera "célula" (ps. 21, 22). El argumento es fuertemente homilético más que teológico y un tanto extraño al afirmar que lo que se perdió en el Edén fue la verdadera comunidad (p. 31). Entonces la comunidad pasa a ser casi un elemento soteriológico: "Los grupos redentores de personas que se rehúsan a juzgar a los demás, por medio del poder del Espíritu Santo, realmente pueden revertir la caída" (p. 31).

Se enseña que la iglesia debe cultivar valores como la aceptación, el amor, la afirmación, la tolerancia, etc. Por otra parte se hace un contraste entre el orden jerárquico piramidal (tipo egipcio) y la comunidad tipo círculo con liderazgo disperso. "La comunidad verdadera no puede existir en una organización que ejerza poder jerárquico" (p. 39). Esta es la tesis central: "Los grupos pequeños han de ser el principio organizador central sobre el que se erija la iglesia" (p. 41). Lo contrario sería, según el autor, "un movimiento clerical", un modelo proveniente de "la apostasía de la Edad Media" (p. 41). Otra vez se polarizan las ideas, en tanto que los argumentos son llevados a un límite, más allá de la objetividad.

Se trabaja mucho sobre "el modelo Jetro" (Ex 18:1-19:6): delegación, capacitación, división en grupos. "El propósito de los grupos pequeños es delegar poder, repartir el sacerdocio" (p. 42). Así que el fundamento teológico se edificó sobre la idea de que "Dios es un grupo pequeño", de que lo fueron "Adán y Eva" y "el modelo Jetro" (p. 45).

Entonces se pasa al Nuevo Testamento donde se dice que Jesús fundó un movimiento basado en la comunidad y esparció el liderazgo ( $p$. 47). De nuevo en esta sección se advierte una tendencia a forzar los argumentos y hacer coincidir la Biblia con el esquema de los grupos pequeños. Se hace, por ejemplo, la afirmación de que "Jesús no trató de ganar multitudes", sino que "se centró en un grupo pequeño de personas" (p. 48). Repite 
que "los grupos pequeños fueron la esencia del estilo ministerial de Jesús" (p. 50). Como ilustración se habla del trabajo de dos en dos.

Con este basamento se hace oposición al modelo de "que cada iglesia tenga su propio pastor" (p. 53). Continúa la exposición al sugerir que "la iglesia primitiva, inmediatamente después del Pentecostés, ya estaba dividida en grupos pequeños" (p. 61). Se dice que las reuniones grandes eran de naturaleza evangelizadora. En medio de estas ideas va emergiendo una eclesiología difícil de identificar con claridad: "No es una iglesia con grupos pequeños, sino una iglesia que es grupos pequeños" (p. 64). Se dice que así fue en los primeros tres siglos de la iglesia. "No necesitaban reunirse con un grupo mayor a fin de ser iglesia" (p. 67). La iglesia institucionalizada habría surgido en tiempos de Constantino (p. 68).

A continuación dice que nuestras iglesias son institucionales y que no brindan comunidad. Tal declaración parece injusta toda vez que se intenta comparar a las iglesias adventistas con las católicas del Medioevo. "El modelo institucional de iglesia que utilizamos hoy era desconocido en la experiencia de la iglesia primitiva" (p. 71). Ante esta aseveración uno se pregunta, ¿no ha estado guiando el Señor a la iglesia en su desarrollo institucional, muchas veces de la mano de Elena G. de White? El contraste que se hace entre la "comunidad" y la "estructura institucional" es permanente. Se echa mano del ejemplo de Pablo y su ministerio en equipo. Se hacen asimismo declaraciones radicales (¿exactas?): "Jesús nunca envía personas solas" (p. 71). Y siempre los "hogares iglesias" se muestran como ejemplo.

Un punto delicado es el rol de la adoración y de la predicación dentro de la misma. Afirma que la comunidad "generalmente no se encuentra en el servicio de adoración" (p. 79). El autor cuestiona la idea de que la iglesia exista para adorar a Dios: “ $¡$ En realidad, la iglesia del Nuevo Testamento no se reunía para adorar a Dios, sino por camaradería!" (p. 80). Tal declaración parece desafortunada. Pero el libro insiste: "La idea de que un servicio de adoración sea la principal función de la iglesia es una reliquia de la Edad Media" (p. 81). El reduccionismo está presente: "La comunión es adoración" (p. 82). También cuestiona la predicación, al decir que rara vez se daba en el Nuevo Testamento, salvo en contextos de evangelización (p. 83). A su entender "parece extraño que la iglesia actual haya hecho de la predicación el enfoque central de la adoración cristiana..." (p. 83). El argumento sube de tono al cuestionar el énfasis cognoscitivo del adventismo y el descuido del aspecto relacional.

La reseña histórica de los grupos pequeños es muy sesgada. Puede resumirse así: (a) El paradigma de hogares iglesias (siglos I-III), sin edificios 
de iglesias o con edificios pequeños; (b) iglesia institucional, desde Constantino (siglo IV en adelante); (c) el metodismo de John Wesley (siglo XVIII) y su organización en clases como requisito de membrecía, con reuniones semanales de diez a doce personas una vez por semana y con líderes laicos; (d) el adventismo de los pioneros, con raíces metodistas, con una actividad llamada "reunión social". El libro afirma que al seguir el paradigma medieval "hemos aceptado el vino de Babilonia" (p. 97). El ejemplo de la iglesia del pastor Cho vuelve a citarse (p. 100).

El autor insiste en el enfoque no doctrinal, no intelectual, de esas reuniones relacionales: "El estudio bíblico era utilizado sólo para mejorar las relaciones. Estas no eran reuniones cognoscitivas sino relacionales" (ps. $100,101)$. Tal vez el libro debió decir también que este énfasis metodista derivó en el pentecostalismo y en el carismatismo que ciertamente difiere del adventismo.

A este tema de la "reunión social" se dedica un extenso capítulo. Dice que los adventistas habían tomado la idea de la reunión de oración metodista y de las reuniones de clases. Esta se hacía muchas veces luego de la predicción o de una reunión de evangelización, o de la Escuela Sabática. También se hacían por separado. Se saca la conclusión de que era más importante que el servicio de predicación y que eran de naturaleza relacional, sin estudios bíblicos ni énfasis doctrinal. Había testimonios breves, confesiones, oración, palabras de ánimo, canto; pero no había estudio bíblico.

Antes de avanzar deben decirse por lo menos dos cosas: la reunión social servía muchas veces como respuesta al estudio y la predicación de la Biblia; además de que estas reuniones sociales se hacían en conjunto y no eran, por tanto, equivalentes a los grupos pequeños, como el autor pretende. Es por tanto exagerada esa reticencia a reconocer la importancia del estudio de la Escritura. Dice: "Las reuniones regulares de la iglesia tenían más que ver con el aspecto relacional que con el cognoscitivo" (p. 116). Cabe preguntarse si una afirmación tal realmente hace justicia a la historia del adventismo primitivo, donde el estudio de las verdades bíblicas consumía gran parte de la actividad.

Tal parece que el esfuerzo por recalcar lo relacional es exagerado. No es correcto afirmar que "los líderes de la iglesia primitiva parecen haber estado más interesados en la experiencia relacional de los creyentes que en su pureza doctrinal" (p. 117). Basta tomar una concordancia y buscar la palabra "doctrina" para advertir la importancia que le da el Nuevo Testamento. Es igualmente improbable lo que se afirma del adventismo: "El sábado por la mañana en las primeras iglesias adventistas no era tanto un tiempo 
para predicar sino para ofrecer testimonios y alabanza" (p. 119). Luego el autor intenta poner un equilibrio entre lo relacional y lo cognoscitivo.

Se cita entonces a Elena G. de White como la persona que más escribió sobre la reunión social, con unas 300 referencias en sus escritos (p. 120). El autor argumento que en reuniones grandes la Sra. White aconsejó dividir a la congregación en grupos más pequeños con un líder designado. Dice también que luego de la muerte de Elena de White estas reuniones se debilitaron y fueron sustituidas por reuniones de oración (p. 135).

Viene entonces todo un capítulo titulado "Elena de White y los grupos pequeños". Él capítulo contiene buenas declaraciones, pero parte de una presuposición: que la reunión social era similar a los grupos pequeños modernos (p. 141). En ese momento vuelve a insistir en que era una experiencia relacional, no cognoscitiva. Para lograr el equilibrio Burrill propone tener dos clases de grupos: los relacionales y los de estudio bíblico. Se dice que en realidad Elena G. de White utilizó pocas veces la expresión "grupo pequeño", más bien habló de "compañías pequeñas". Cuando se toman sus declaraciones pueden verse los objetivos que la autora tenía en mente: trabajar por miembros de iglesia y por los incrédulos, estudiar la Biblia, orar e interceder, dar testimonio, servir y ayudar a los creyentes aislados. Tal parece que estas citas de la Sra. White proveen de un mayor equilibrio que todo el desarrollo de los libros que estamos comentando.

Al final el autor sólo da dos opciones: existir como iglesia institucional o como iglesia de grupos pequeños (p. 154). Para que los grupos puedan funcionar debe redescubrirse una mentalidad misionera y debe creerse en el ministerio de los laicos. Se dice también que los grupos pequeños no deben ser opcionales: "Es más adecuado que el servicio de adoración del sábado de mañana sea opcional" (p. 156).

En la estructura de iglesia que se promueve para el siglo XXI: "Las reuniones grandes pueden darse en forma semanal, mensual o trimestral. No tendría importancia, dado que el grupo pequeño y no la reunión grande es la sangre vital de la iglesia" (p. 158). No podemos sino concordar con esta declaración: "Los adventistas nunca podemos descuidar el estudio de la Biblia" (p. 160). Sin embargo se argumenta a favor de la Escuela Sabática seguida por una reunión de testimonios y no necesariamente por un sermón. Los interesados se relacionarían primero con el grupo pequeño. El equilibrio a veces parece perderse: "Puede haber algún momento para el estudio de la Biblia en la reunión del grupo pequeño, pero si es así, será de naturaleza relacional y no cognoscitiva. El estudio bíblico cognoscitivo está reservado 
para la escuela Sabática" (p. 162). Se sugiere no tratar de combinar lo relacional con lo cognoscitivo en la Escuela Sabática.

En cuanto a la función pastoral, ésta se limitaría a la educación de los líderes de grupos pequeños y a los servicios generales cada semana, mes o trimestre, además de las tareas evangelizadores en nuevos territorios. La estructura de la iglesia cambia: "Nuestra iglesia actual se basa principalmente en los programas y está estructurada por departamentos... El nuevo paradigma es una iglesia donde el grupo pequeño es el principio organizador sobre el que se basa toda la iglesia" (p. 169).

Russell Burrill es un escritor dinámico, claro y convincente. Muchos de sus pensamientos son excelentes y dignos de consideración. Es un llamado a reexaminar la situación de la iglesia y de su ministerio. Parece, sin embargo, que la argumentación bíblica e histórica es de a ratos insuficiente, fragmentaria y polarizadora. Los grupos pequeños deben apoyarse, tal vez con un fundamento más adecuado; al mismo tiempo que se pueda pensar en la iglesia, su identidad, su doctrina, su ministerio y su experiencia dinámica de culto. Muchas preguntas quedan sin responder, así como la exhibición de ámbitos donde esta estructura esté funcionando. Queda claro, en suma, que el tema de los grupos pequeños y de la propia eclesiología adventista, necesitan seguir estudiándose.

Daniel Oscar Plenc

Ellen G. White Research Center email: ciwdirec@uapar.edu

Recibido: 11 de Setiembre de 2012 Aceptado: 25 de Octubre de 2012

\section{Referencias}

Burrill, R. (1996). Radical Disciples for Revolutionary Churches. Fallbrook, California: Hart Research Center.

Burril, R. (2008).Discípulos modernos para Iglesias revolucionarias, trad. Claudia Blath. Buenos Aires: Asociación Casa Editora Sudamericana.

Burril, R. (2007). La iglesia revolucionada del siglo XXI, trad. Claudia Blath. Buenos Aires: Asociación Casa Editora Sudamericana. 